\title{
Truth-telling to Patients with Advanced Cancer: A Comparison between Cancer center, University Hospitals, General City Hospitals, and Private General Practitioners in Japan
}

\author{
Satoshi Morita ${ }^{1)}$, Michiya Kobayashi ${ }^{2)}$, Koji $\mathrm{Oba}^{3)}$, \\ Toru Ichihara ${ }^{4)}$, Akimasa Nakao, ${ }^{5}$, Junichi Sakamoto ${ }^{3)}$ \\ ${ }^{1)}$ Department of Epidemiology and Health Care Research, Kyoto University Graduate School of Medicine, Kyoto, Japan, \\ ${ }^{2)}$ Department of Surgery, Kochi University, Kochi, Japan, ${ }^{3)}$ Department of Epidemiological \& Clinical Research \\ Information Management, Kyoto University Graduate School of Medicine, Kyoto, Japan, ${ }^{4)}$ Department of Surgery, \\ Toyohashi National Hospital, Aichi, Japan, ${ }^{5}$ Second Department of Surgery, Nagoya University, Aichi, Japan
}

\begin{abstract}
Attitude of Japanese doctors in their practice of truth-telling to patients with non-curable terminal cancer was extensively investigated to evaluate the difference between doctors from various types of medical institutions. A semi-structured interview using a questionnaire consisting of 18 items covering the doctors' attitudes towards truth-telling and their styles of informing patients about cancer diagnosis and prognosis was performed. Nominal responses to the questions were compared among 10 physicians from 1 cancer center, 71 from 7 university hospitals, 62 from 5 city hospitals, and 50 private general practitioners. The physicians from university hospitals, general city hospitals and/or general practitioners have significant tendencies that they were reluctant to tell negative information to patients both in terms of their inner perceptions as well as in their real clinical practice compared with those at cancer center from various viewpoints: seven perceptive questions ( $p<$ $0.05)$ and five practice questions $(\mathrm{p}<0.05)$. This study shows that physicians in university hospitals, general city hospitals or private practitioners tell the truth in a less qualitatively and quantitatively explicit manner than those at the cancer center when caring patients with terminal-stage cancer in Japan.
\end{abstract}

Key Words: Truth-telling, advanced cancer, informed consent

(Received November 16, 2005; Accepted March 6, 2006)

\section{Introduction}

Respect for patient autonomy has become a prerequisite in the medical decision making in the world. However, even in the Western countries, disclosure or truth-telling of a cancer diagnosis and prognosis of the advanced stage patients is a relatively recent phenomenon $^{1)}$. For example, even in the US, $88 \%$ of the doctors generally did not inform their cancer patients in $1961^{2)}$, whereas by $197998 \%$ generally turned out to do so ${ }^{3)}$. Nowadays, physician-patient communication has become characterized by patient autonomy which has become institutionalized by legally imperative informed consent procedures and the ideal of "truth-telling" information disclosure. In this regard, in placing patient autonomy

Correspondence to: Satoshi Morita, PhD, Department of Epidemiology and Health Care Research, Kyoto University Graduate School of Medicine Yoshidakonoecho, Sakyo-ku, Kyoto 606-8501, Japan. Phone: +81-75-753-4645, Fax: +81-75-753-4644. E-mail: satoshi_morita@pbh.med.kyoto-u.ac.jp at the center of ethical decisions, the current medical community in the world has proceeded as if this were universally appropriate reality. However, some other countries $^{4,5)}$ and even among some cultural groups in the $\mathrm{US}^{6,7)}$ have not accomplished the recent paradigm shift. Truth-telling and accompanying informed consent may, therefore, complicate and possibly interfere with the care of certain group of patients ${ }^{8}$, particularly those from countries and cultural groups in which the family or other social unit plays a more pivotal role in treatment decisions $^{9,10)}$.

In Japan, according to the survey of the Ministry of Health and Welfare, only $20 \%$ of recently died patients had been told the truth, having advanced and lethal cancer. This fact suggested that most of the clinical trials on cancer in Japan registered and enrolled patients without real informed consent and patients' autonomic decisions ${ }^{11)}$. Effort of the Japanese Clinical Oncology Group tried to break through the situation, and "Guidelines for Telling the Truth to Cancer Patients" was published in 
1996 from the group of Japanese National Cancer Center Hospital $^{12)}$. Despite those efforts, large proportion of Japanese doctors and even patients themselves believe that the patients should not be informed the truth of an incurable cancer diagnosis ${ }^{13,14)}$.

The present study carried out examination of possible differences in attitudes and perceptions of truth-telling and styles and experiences in disclosure of diagnoses and prognoses of cancer among the four strata of Japanese doctors according to their institutions (cancer center/ university hospitals/ general city hospitals/ private practitioners).

\section{Subjects and Methods}

\section{Subjects}

From February 2000 to July 2002, we carried out semi-structured interviews for 193 Japanese physicians from various specialties having experience managing advanced or terminal cancer patients. This investigation was conducted using a questionnaire regarding attitudes and practices in disclosing cancer-related information. We enrolled physicians from one cancer center and seven university hospitals and five general city hospitals, and fifty private general practitioners. None of the institutions had a stated policy with respect to disclosure of the diagnosis of cancer.

\section{Questionnaire and Semi-structured Interview}

We constructed a questionnaire consisting of eighteen questions of which eleven (Q1-Q11) covered attitudes towards and perceptions of truth-telling and the remaining seven (Q12-Q18) covered their styles and experiences of informing patients of diagnosis and prognosis (see Appendix). We based the questionnaire on Miyaji ${ }^{15,16)}$ examining perceptions of American physicians about their practice for truth-telling in the care of dying patients. As results of the interview that she performed, those eighteen items along with several categories of response were generated. The questionnaire additionally included the demographic information (i.e., age and sex).

Three expert surgical oncologists (JS and his colleagues MK and TI) who have over 20 years of clinical experience interviewed the Japanese physicians. They explained the objectives of our research and detailed the meaning of each question to the participating physicians. The semi-structured interview was conducted in a one-on-one and face-to-face fashion. The interviewers ensured that information was not shared among the physicians. In the interview, advanced or terminal cancer patients were defined for the interviewed physicians as patients who have a $5 \%$ or less probability of surviving over 3 years. Group discussion was carried out to standardize these interview procedures among the interviewers before initiating the interview.

\section{Statistical Analyses}

Comparisons of nominal responses to the questions were carried out among four groups: 1) the Japanese physicians from one cancer center; 2) those from seven university hospitals; 3) those from five general city hospitals; and 4) those from the fifty private general practitioners. An exact p-value for the observed tables was calculated and used to determine significant differences in the responses among the groups. Median and range of age and frequency of sex was calculated in each of the three groups. The SAS for Windows release 8.02 (SAS Institute Inc., Cary, NC, USA) was used for these statistical analyses.

\section{Results}

Ten physicians worked for one cancer center. 71, 62 and 50 physicians were seven university hospitals, five general city hospitals and private general practitioners respectively. Nine of 193 subjects were female. One worked for the cancer center, while eight were from the city hospitals. Age of the physicians ranged from 32 to 56 (median: 44) in the cancer centers, ranged from 27 to 65 (median: 41) in the university hospitalss, ranged from 26 to 59 (median: 39) in the city hospitals, and ranged from 27 to 69 (median: 42) for the general practitioners. It took around twenty minutes on average ( 30 minutes at maximum) to complete the interview, and there were no large differences in time for the interview among the four groups.

\section{Attitudes toward and Perceptions of Truth-telling}

Q1, Q2, Q3, Q7, Q8, Q10, and Q11 were those in which statistically significant differences in frequencies between the three groups, as presented in Fig. 1. There were no statistically significant differences with respect to the other questions.

Regarding Q1 (telling what patients want to know), the physicians from the cancer center were more likely to consider that they should tell patients what the patients want to know, in comparison with the other three groups $(\mathrm{p}=0.007)$. When patients explicitly claim that they do not want to know (Q2), the physicians from university hospitals, general city hospitals and the private general practitioners were more likely to tell the family than those from cancer center $(\mathrm{p}<0.001)$. When patients wanted to give their information (Q3), the physicians from cancer center were more likely to tell all information $(\mathrm{p}=0.005)$. In case that the family required to restrict information to patients (Q7), more doctors from cancer center said that they would make efforts to persuade the family ( $\mathrm{p}<0.001$ ). The style of truthtelling (Q8) was more likely influenced by colleagues in the physicians from cancer center $(\mathrm{p}=0.044)$. With respect to Q10 (time for truth-telling), the physicians at 
[Q1: We should inform patients as much as they want]

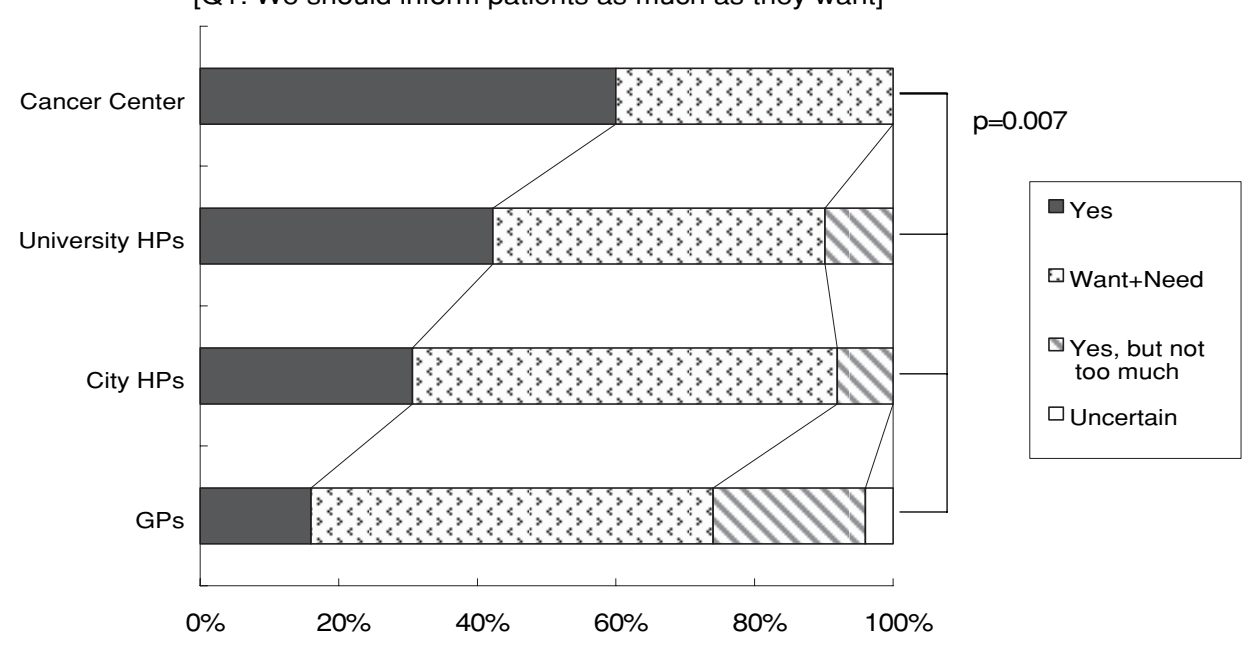

[Q2: I tell the truth to patients who are unwilling to know]

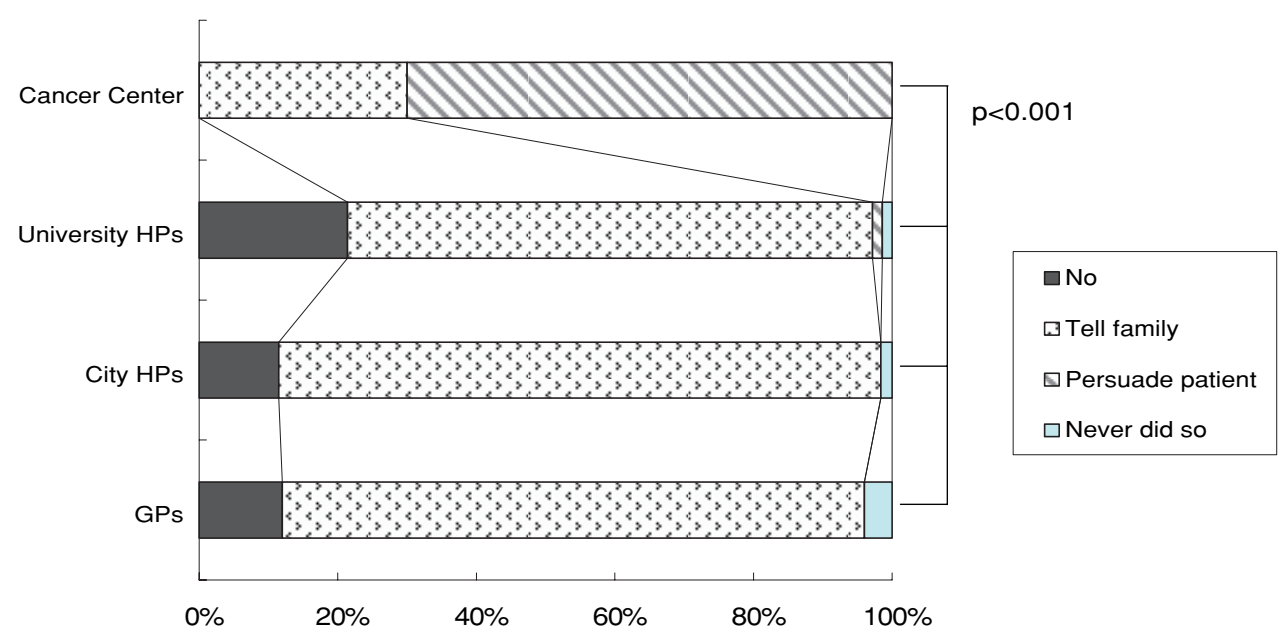

[Q3: We should not lie when giving patients information]

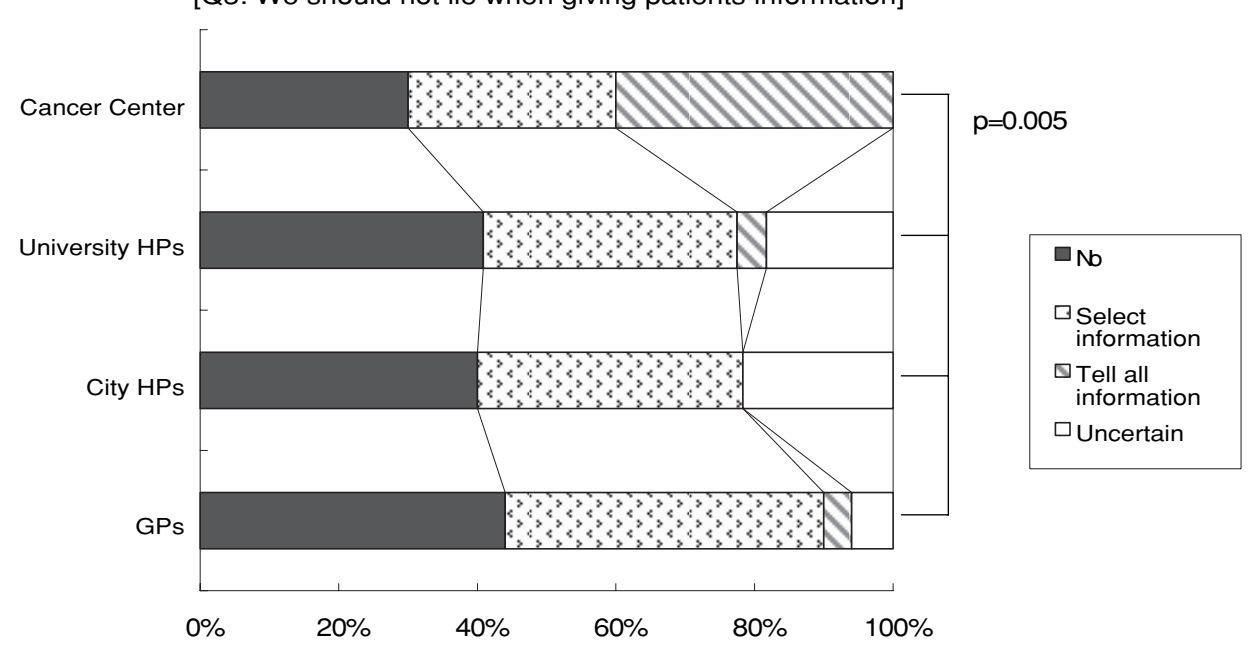

Fig. 1 Responses to items regarding physicians' attitudes and perceptions of truth-telling among physicians from one cancer center (Cancer Center), those from seven university hospitals (University HPs), those from five general city hospitals (City HPs), and fifty private general practitioners (GPs). 
[Q4: I do respect patient's rights to know the truth regardless of disease stage]

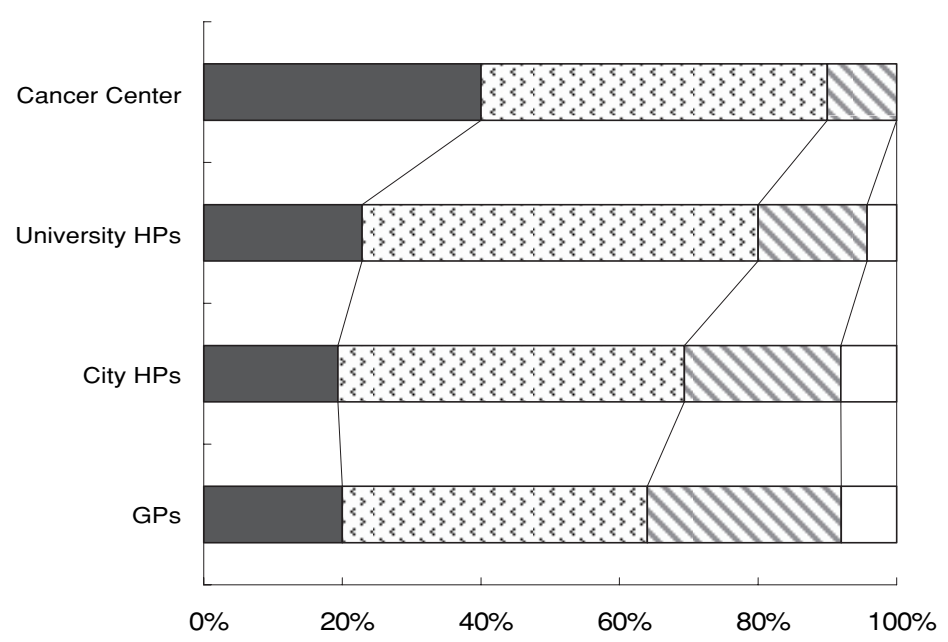

\begin{tabular}{|l|}
\hline Yes \\
$\square$ Detail \\
explanation \\
$\square$ Depends on \\
stage \\
$\square$ Uncertain
\end{tabular}

[Q5: I give patients optimistic / pessimistic estimation]

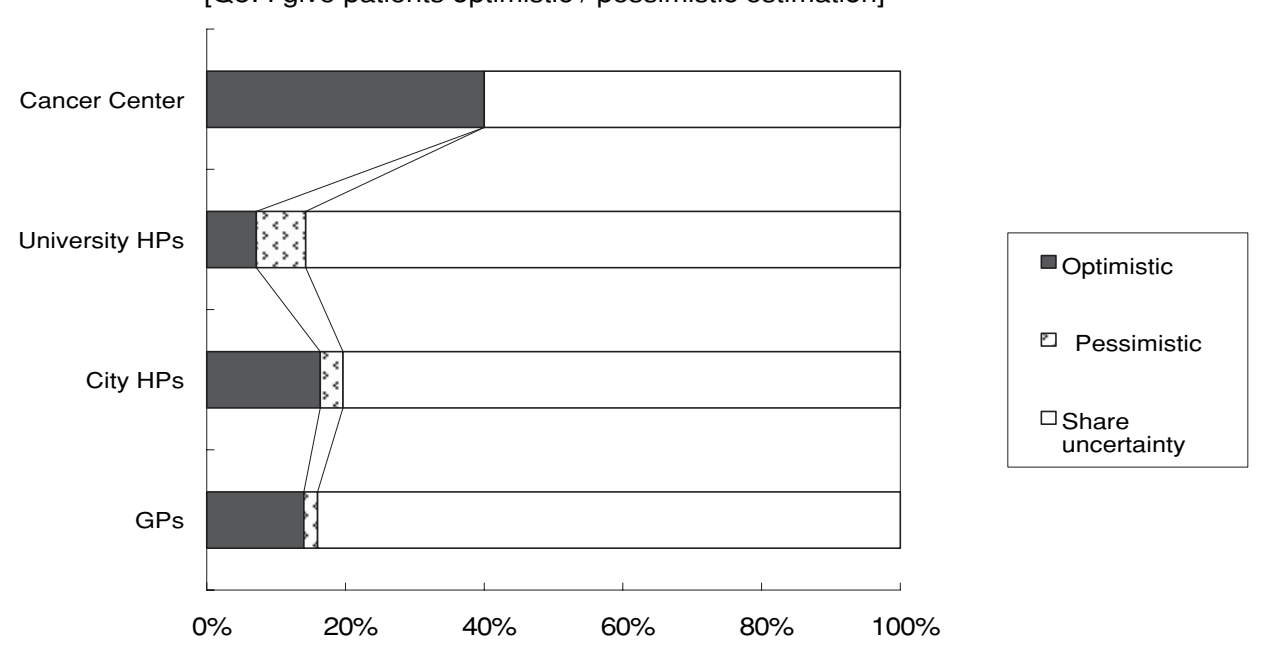

[Q6: I tell the truth to patients in company with someone else]

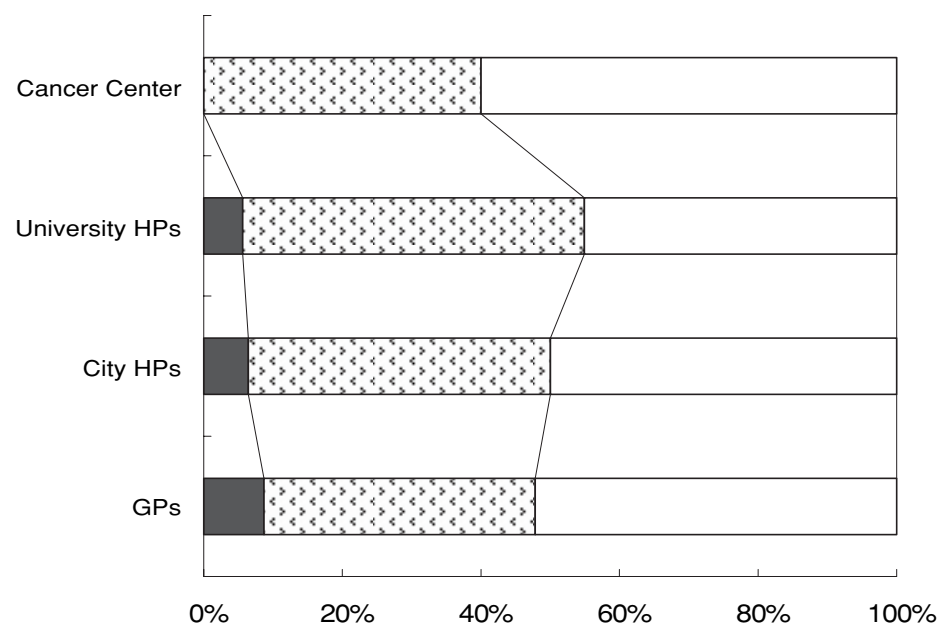

$\square$ No. Patient
alone
$\square$ Yes
$\square$ Depends

Fig. 1 continued 


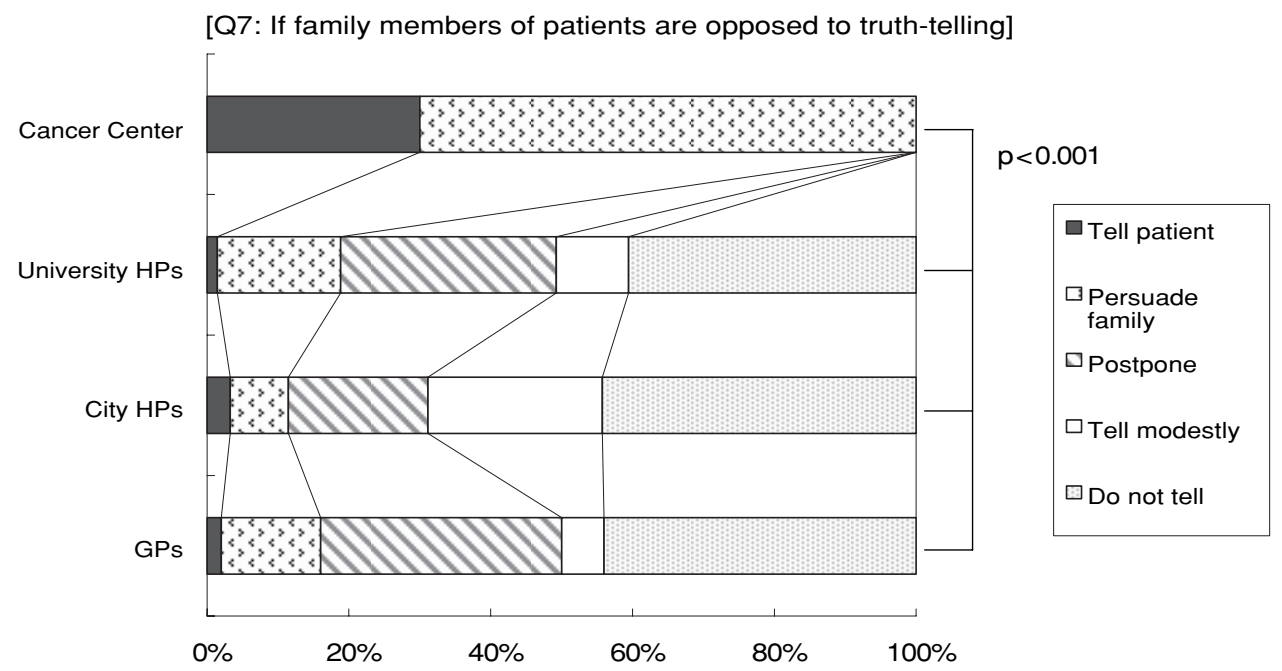

[Q8: My style of truth-telling was influenced by]

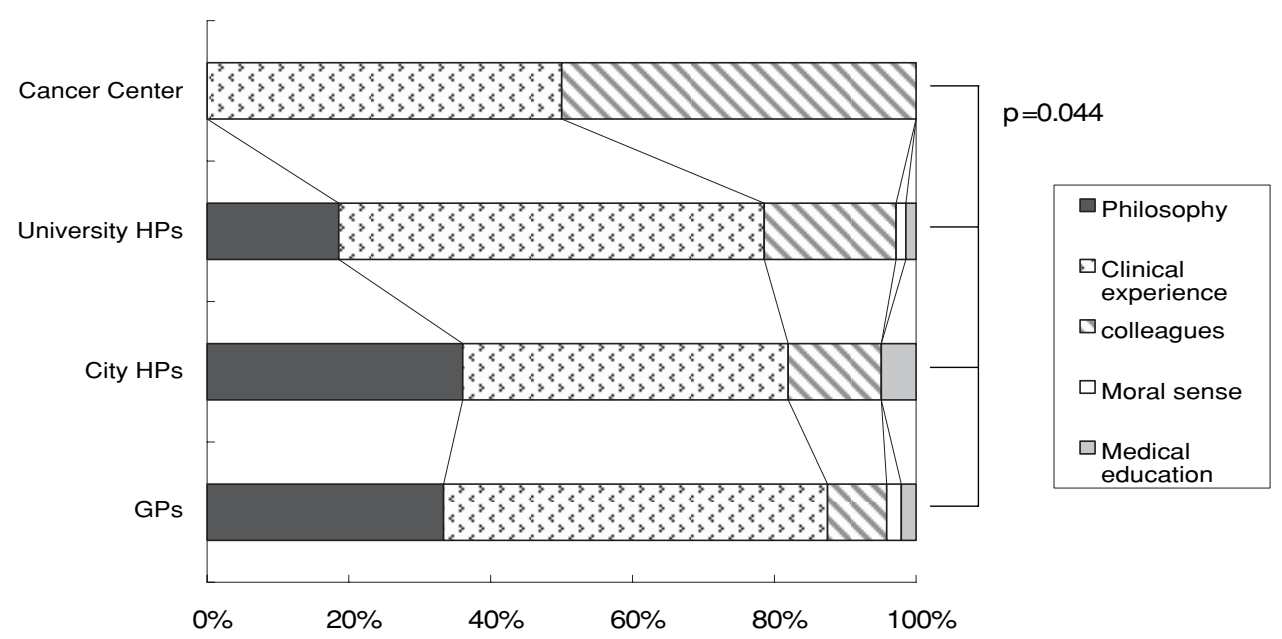

[Q9: We should tell the truth indirectly]
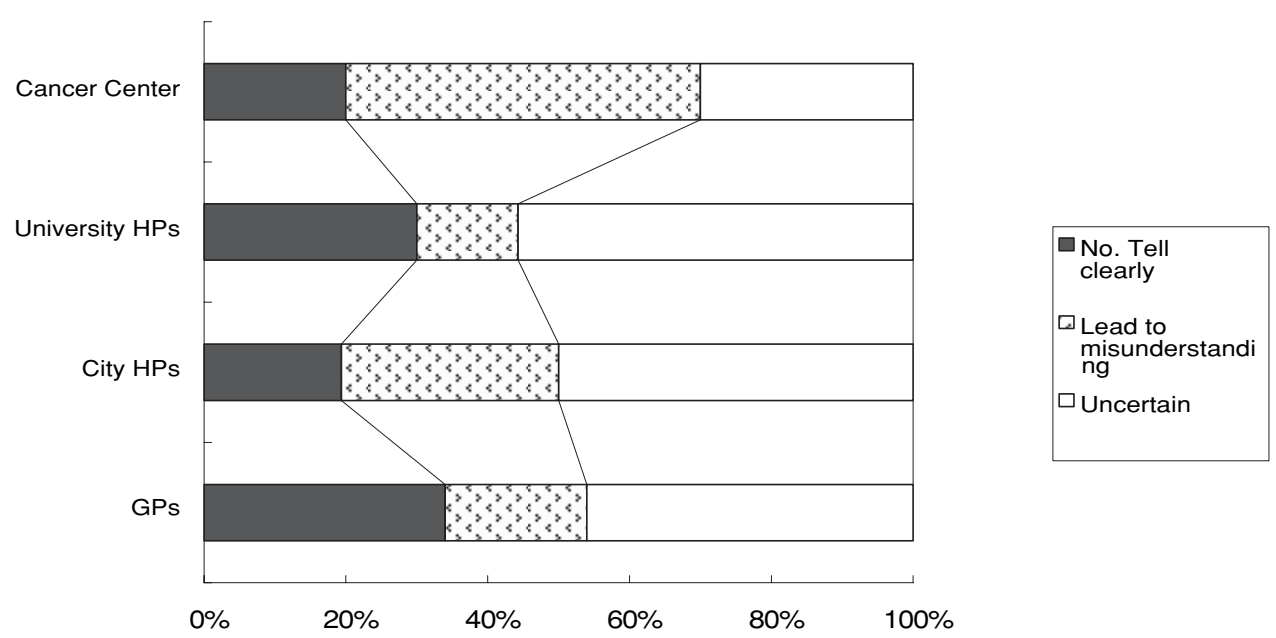

Fig. 1 continued 


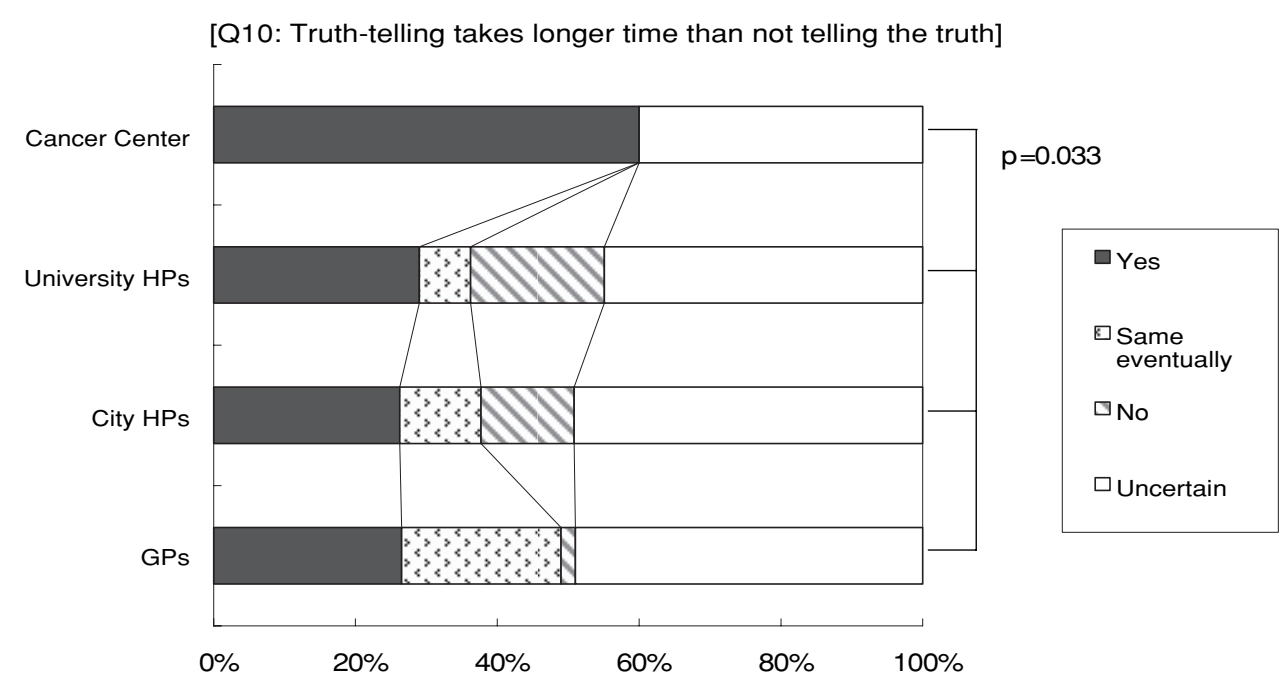

[Q11: I feel the truth-telling as]

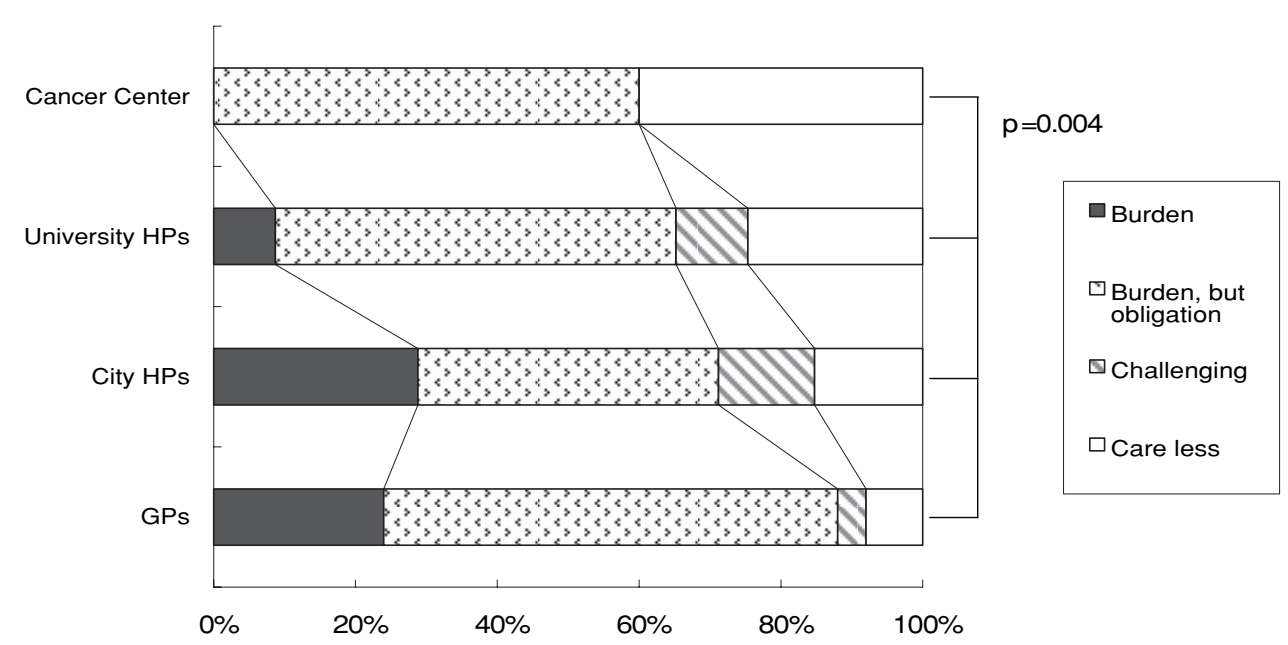

Fig. 1 continued

the private general practitioners had higher tendencies to consider that they are not pushed for time to tell the truth and there is no clear deadline for disclosure of the truth ( $p=0.033$ ). With respect to Q11, the physicians at cancer center were less likely to feel the truth-telling burdensome than the other three groups $(\mathrm{p}=0.004)$.

\section{Styles and Experiences of Disclosure of Diagnosis and Prognosis}

There were statistically significant differences in frequencies of responses to Q12, Q14, Q15, Q17, and Q18, as presented in Fig 2, but not in those to the other questions.

The disclosure of diagnosis (Q12) appeared to be performed more actively by the physicians at cancer center $(100 \%)$ than the other three groups $(57 \%, 49 \%$ and $47 \%)(\mathrm{p}<0.001)$. Similar tendencies were observed in the comparisons with respect to the proportion of patients who know that they are dying (Q14: $\mathrm{p}=0.012)$. Regarding the disclosure of prognosis (Q15), the physicians at cancer center tended to more clearly give the patients information on their prognosis than especially the private general practitioners $(\mathrm{p}=0.010)$, in terms of more frequent uses of statistics $(\mathrm{Q} 18: \mathrm{p}<0.001)$. In university hospitals, the physicians used numbers for disclosure more than the other three groups $(\mathrm{p}=0.016)$. 
[Q12: Percent of dying patients know diagnosis]

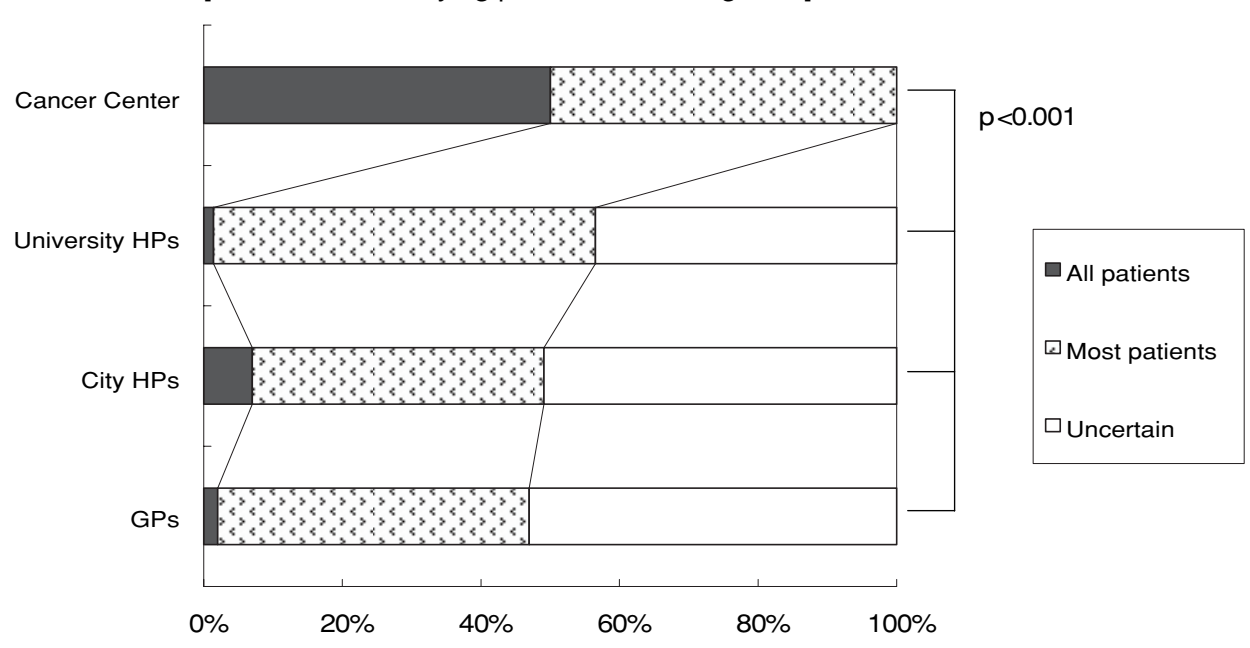

[Q13: I tell information that can lead to patient's refusal to receive anti-cancer treatment]

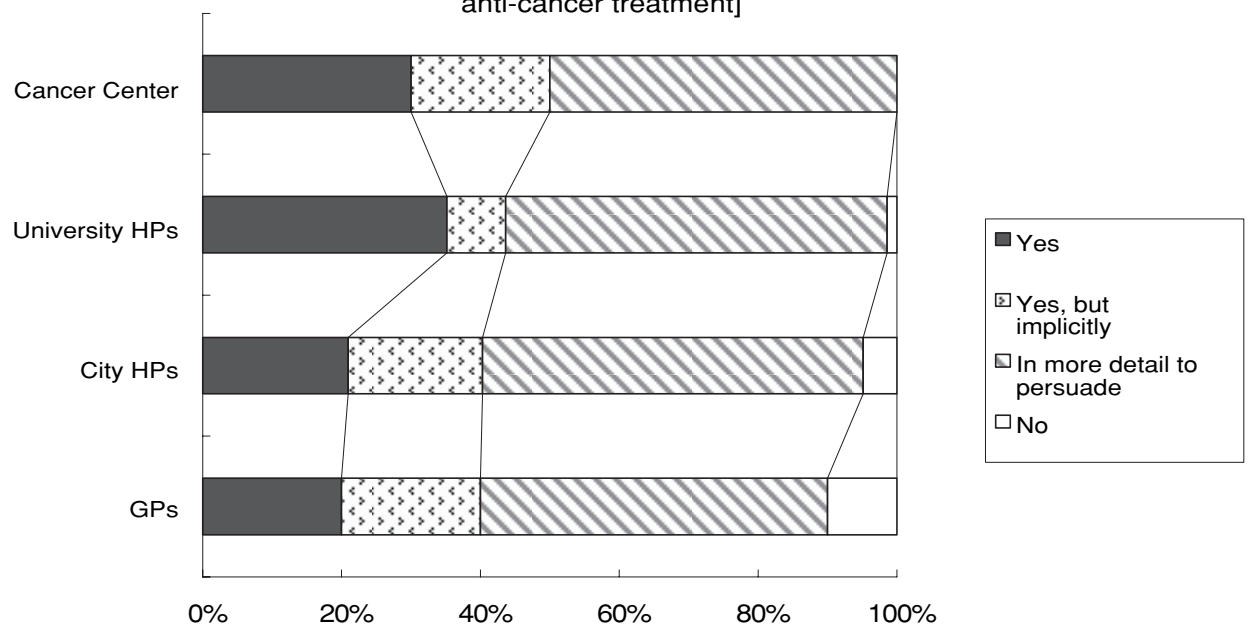

[Q14: Percent of dying patients know that they are dying]

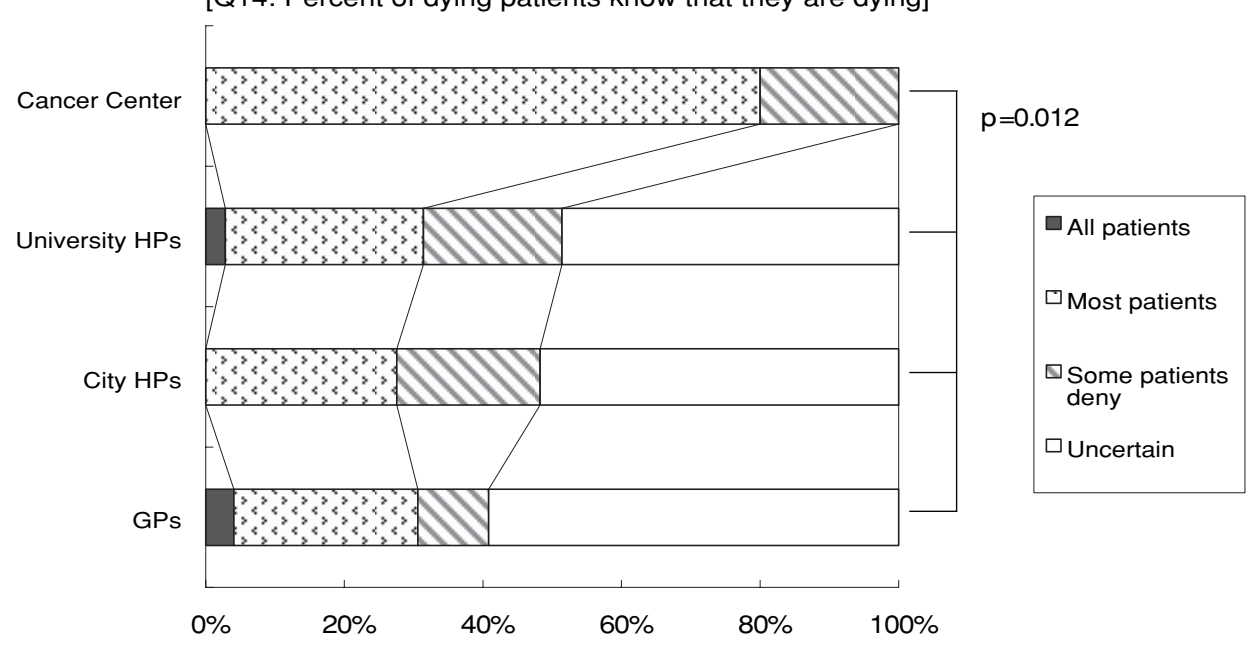

Fig. 2 Responses to items regarding physicians' styles and experiences of disclosure of disease among the four groups of Japanese physicians (Cancer Center, University HPs, City HPs, and GPs). 
[Q15: I explicitly tell patients that they are dying (poor prognosis)]

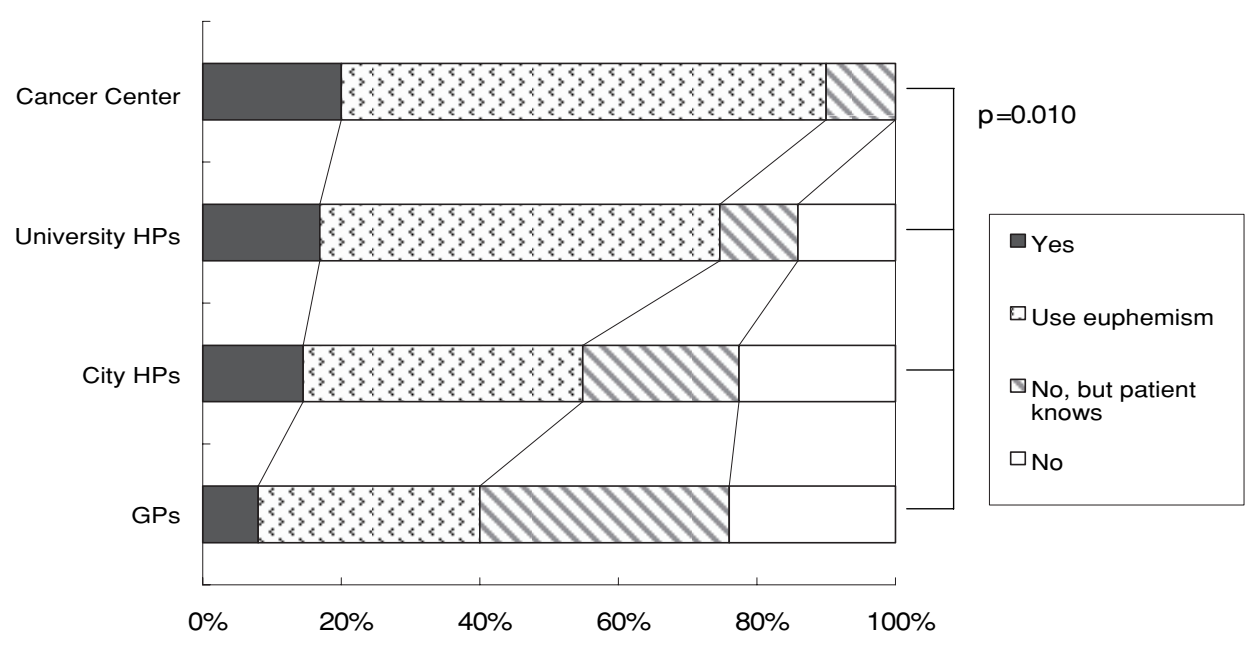

[Q16: Patients know approximately how long they can live]

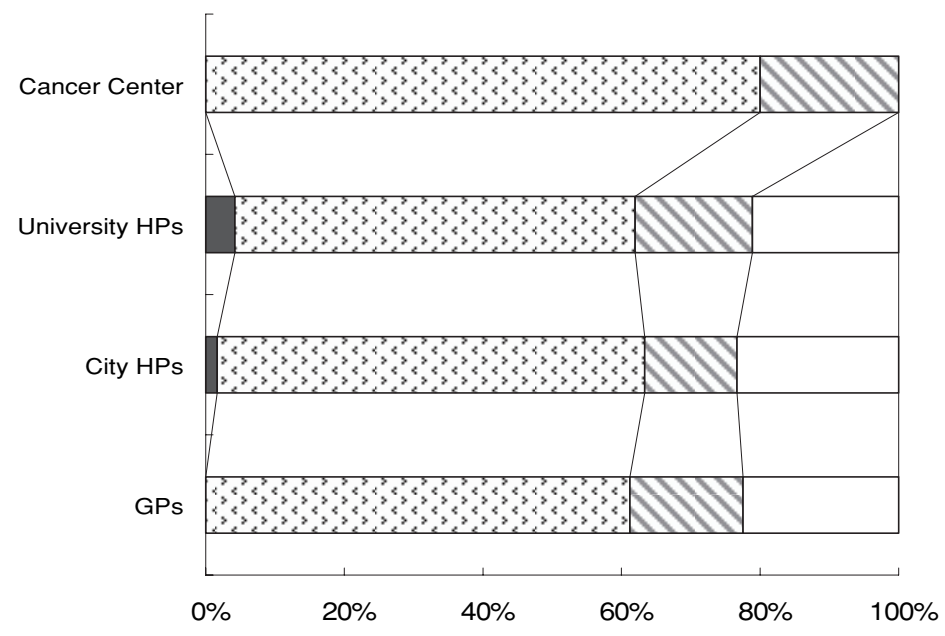

\begin{tabular}{|l}
$\square$ Yes \\
$\square$ In broad range \\
$\square$ Optimistic \\
estimate \\
No
\end{tabular}

[Q17: I use numbers in telling patients]

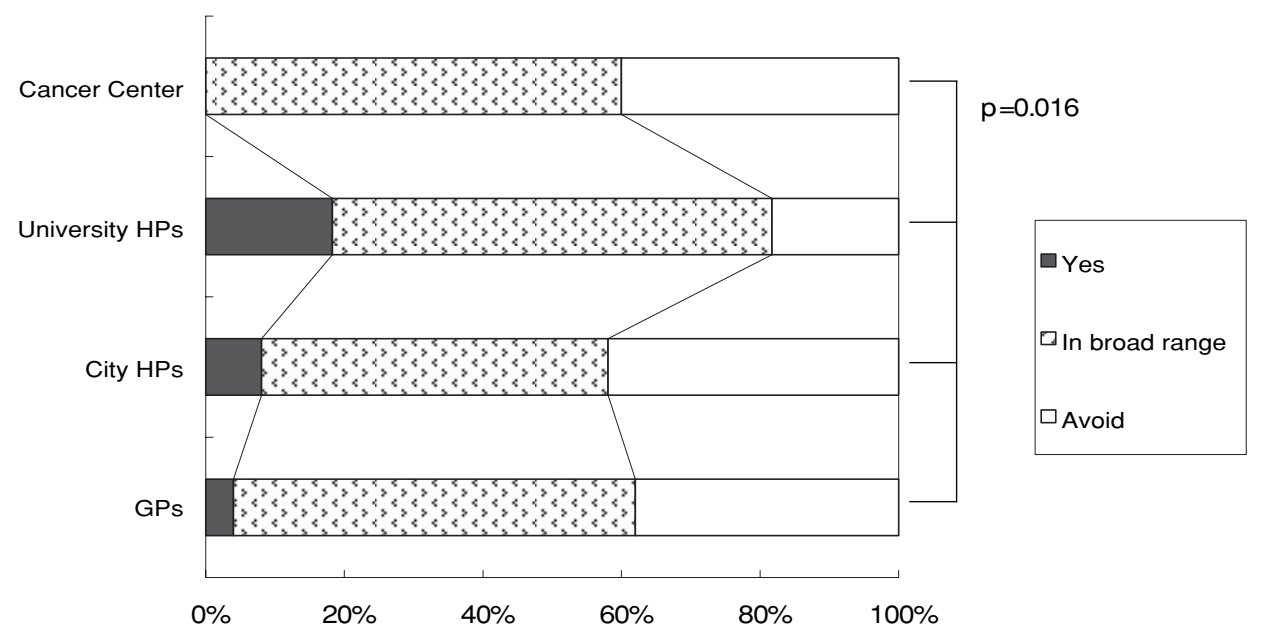

Fig. 2 continued 


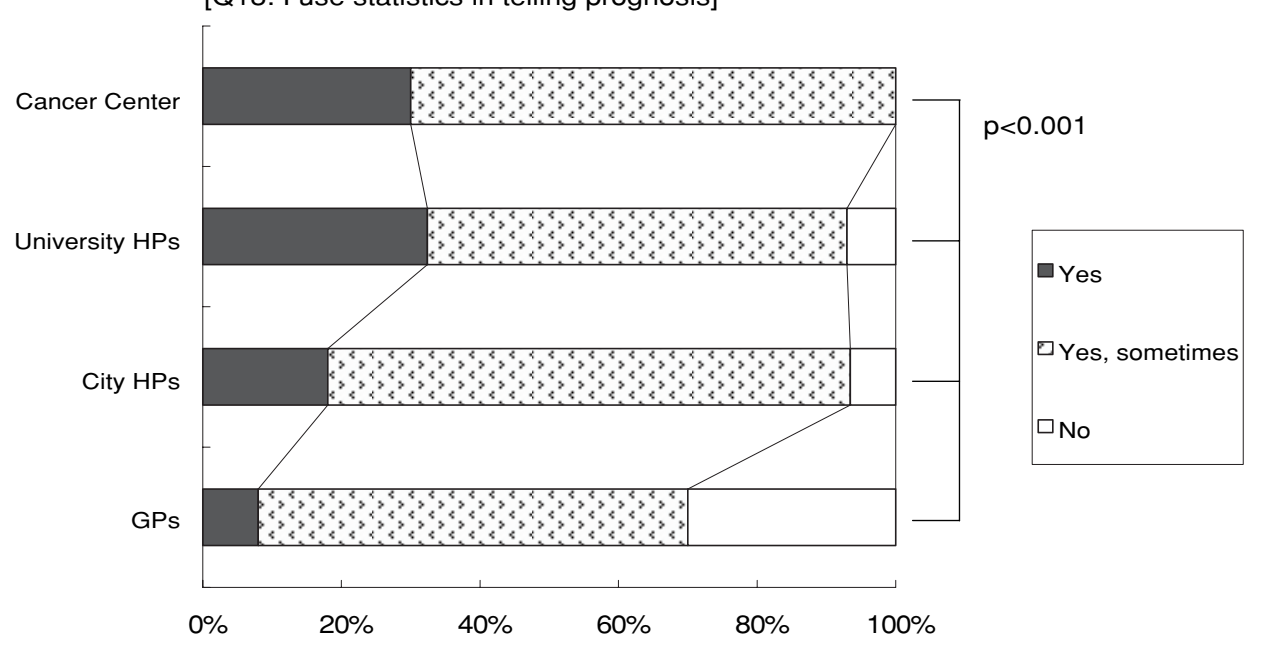

Fig. 2 continued

\section{Discussion}

The issue on truth-telling is at the core of contemporary biomedical ethics. Differences in truth-telling arise from the intricate interplay between autonomy and beneficence in medicine, and sometimes, under the influence of cultural variables. Recently, a trend toward evolution of truth-telling practices has been advocated in countries previously known for non-disclosure of the truth regarding incurable cancer to the patients.

Obviously, Japan was among them, and most of the Japanese medical professionals have long believed that their practice is beneficial for the treatment of advanced cancer patients, as well as favorable to maintain physician-patient relationships. Recently, shift toward the western autonomy predicament has gradually taken place. The present study clarified the up-to-date condition of truth-telling to cancer patients by the extensive semi-structural interview method involving nearly two hundred Japanese medical doctors of various specialties and institutions. Analysis of results of this colossal survey demonstrated that the evolution of truth-telling in Japan is certainly progressing. However these results also demonstrated that the trend has not necessarily been accepted among all the strata of the physicians. The present survey classified the doctors into several categories according to their institutions and their style of practice, and by some group of physicians truth-telling for advanced cancer patients has not yet been sufficiently presented. In several leading institutions of Japan, truthtelling is taken for granted as a prerequisite for obtaining informed consent. Our research showed that the physicians at university hospitals, general city hospitals and especially the general private practitioners are more likely to withhold the truth-telling. It is surprising that they are significantly less likely to consider that they should tell patients what the patients want to know (Q1; $\mathrm{p}=0.007$ ) or to say definitely about their poor prognosis (Q15; $\mathrm{p}=0.010)$, and chooses to tell the truth to the family members instead of the patient himself when he seems to be reluctant to hear about his illness $(\mathrm{Q} 2 ; \mathrm{p}<0.001)$ compared to the cancer specialists working in the cancer center.

However, it should always be reminded that when a physician tries to give an accurate truth telling, precise data according to the Evidence Based Medicine (EBM) is imperative. Even in cancer center, explanations are likely to be given mostly based on the EBM results from the western countries, and it is possible that these diagnosis, treatment, and prognosis data does not necessarily adequate to the Japanese patients.

Practical implication of this survey strongly suggests that the conceptual reform of the doctors working in city general hospitals towards the truth-telling in cancer patients is mandatory to persuade patients to clinical trials and to establish own medical evidence from Japan. With regard to the participation of doctors in their own private practice to comply with the accurate truth-telling and eventually to enroll patients into clinical trial, more fundamental approach could be necessary. In order to comply them with contemporizing rule of truth-telling, preliminary educations through lectures instructing its practical procedures as well as teaching its advantage both for the proper practice of doctors for clinical improvement, and also quality of life of the patients of advanced cancers ${ }^{17}$. These kinds of educations could still be necessary, and these activities might also be beneficial to the physicians working in general hospitals, especially for those working in small local cities or in towns.

The present report might have substantial importance by precisely illustrating the present conditions in terms 
of truth-telling situation in Japan. Although there is still a considerable difference between doctors working in cancer center and those who are not, the difference is diminishing. Recent evolution in Japan in terms of truthtelling and obtaining true informed consent have been accelerating $^{18)}$, and we believe that the situation of real truth-telling for advanced or incurable cancer patients has rapidly been approaching to the global standard.

This study carried out the interviews for the physicians from 2000 to 2002 . In the past few years, the environment of cancer disclosure and informed consent has been dramatically changing in Japan. Such change may have taken place also in local hospitals. Accordingly, our findings may not reflect the most up-to-date situation. The latest data regarding participation for clinical trials and the number of accrued patients as well as that of cancer disclosure and informed consent in local hospitals should be analyzed in future studies. Furthermore, it may be important to investigate how to organize educational courses for the truth-telling and informed consent and their effects on progress of clinical trials.

In conclusion, this study shows that physicians in university hospitals, general city hospitals or private practitioners tell the truth in a less qualitatively and quantitatively explicit manner than those at the cancer center when caring patients with advanced or terminal-stage cancer in Japan. Appropriate measures such as education and thereby changing awareness regarding attitude of truth-telling in such major population of Japanese doctors may be able to improve the quality of care for those advanced or terminal-stage cancer patients.

\section{Acknowledgments}

This work is supported in part, by the grant-in-aid from non-profit organization Epidemiological \& Clinical Research Information Network (ECRIN). We thank all the participating physicians and the Okazaki-shi Medical Brotherhood for providing us with the data. We also wish to thank Reiko Yamanishi at the EBM Collaborative
Research Center, Kyoto University Graduate School of Medicine, for data entry and management.

\section{References}

1) Jenkins. V., Fallowfield, L. and Saul, J. (2001). Information needs of patients with cancer: results from a large study in UK cancer centres. Br. J. Cancer 84: 48-51.

2) Emanuel, E. J. and Emanuel, L. L. (1992). Four models of the physician-patient relationship. JAMA 267: 2221-2226.

3) Oken, D. (1961). What to tell cancer patients: a study of medical attitudes. JAMA 175: 1120-8.

4) Novack, D. H., Plumer, R., Smith, R. L., et al. (1979). Changes in physicians' attitudes toward telling the cancer patient. JAMA 241:897-900.

5) Thomsen, O. O., Wulff, H. R., Martin, A., et al. (1993). What do gastroenterologists in Europe tell cancer patients? Lancet 341: 473-476.

6) Glick, S. M. (1997). Unlimited human autonomy: a cultural bias? N. Engl. J. Med. 336: 954-956.

7) Blackhall, L. J., Murphy, S. T., Frank, G., et al. (1995). Ethnicity and attitudes toward patient autonomy. JAMA 274: 820-825.

8) Carrese, J. A. and Rhodes, L. A. (1995). Western bioethics on the Navajo reservation: benefit or harm? JAMA 274: 826-829.

9) Kleinman, A. (1978). Culture, illness, and care: clinical lessons from anthropologic and cross-cultural research. Ann. Intern. Med. 88: 251-258.

10) Holland, J. C., Geary, N., Marchini, A., et al. (1987). An international survey of physician attitudes and practice in regard to revealing the diagnosis of cancer. Cancer Invest. 5: 151-154.

11) Sasako, M. (1996). Getting informed consent in clinical trials on Japanese cancer patients [in Japanese]. Gan To Kagaku Ryoho 23: 146-150.

12) Okamura, H., Uchitomi, Y., Sasako, M., et al. (1998). Guidelines for telling the truth to cancer patients. Jpn. J. Clin. Oncol. 28: 1-4.

13) Gregory, W., Sandra, R., Akamatsu, T., et al. (2000). Ethical decision making and patient autonomy. Chest. 118: 1172-1182.

14) Elwyn, T. S., Fetters, M. D., Gorenflo, W., et al. (1998). Cancer disclosure in Japan: historical comparisons, current practices. Soc. Sci. Med. 46: 1151-1163.

15) Miyaji, N. T. (1993). The power of compassion: truth-telling among American doctors in the care of dying patients. Soc. Sci. Med. 36: 249-264.

16) Miyaji, N. T. (1994). Informed consent, cancer, and truth in prognosis. N. Engl. J. Med. 331: 810-812

17) Aoki, Y., Nakagawa, K., Hasezawa, K., et al. (1997). Significance of informed consent and truth-telling for quality of life in terminal cancer patients. Radiat. Med. 15: 133-135.

18) Shimoyama, N., Murakami, T., Takahashi, H., et al. (2005). Recent changes in informed consent for cancer treatment [in Japanese]. Gan To Kagaku Ryoho 32: 152-155. 


\section{APPENDIX}

A questionnaire used to interview physicians for investigation of their attitudes toward truth-telling.

\begin{tabular}{|c|c|c|c|c|c|}
\hline Item & \multicolumn{5}{|c|}{ Response } \\
\hline $\begin{array}{l}\text { 1. We should inform patients as } \\
\text { much as they want }\end{array}$ & Yes & Want & - Need & $\begin{array}{l}\text { Yes, but not } \\
\text { too much }\end{array}$ & Uncertain \\
\hline $\begin{array}{l}\text { I I tell the truth to patients who are } \\
\text { unwilling to know }\end{array}$ & No & Tell & amily & $\begin{array}{l}\text { Persuade } \\
\text { patient }\end{array}$ & $\begin{array}{l}\text { Never did } \\
\text { so }\end{array}$ \\
\hline $\begin{array}{l}\text { 3. We should not lie when giving } \\
\text { patients information }\end{array}$ & No & $\begin{array}{r}\text { Se } \\
\text { infor }\end{array}$ & ect & $\begin{array}{c}\text { Tell all } \\
\text { information }\end{array}$ & Uncertain \\
\hline $\begin{array}{l}\text { 4. I do respect patient's rights to } \\
\text { know the truth regardless of disease } \\
\text { stage }\end{array}$ & Yes & $\begin{array}{r}\text { De } \\
\text { expla }\end{array}$ & tail & $\begin{array}{l}\text { Depends on } \\
\text { stage }\end{array}$ & Uncertain \\
\hline $\begin{array}{l}\text { 5. I give patients optimistic } \\
\text { pessimistic estimation }\end{array}$ & Optimis & & Pessimisti & Share & uncertainty \\
\hline $\begin{array}{l}\text { 6. I tell the truth to patients in } \\
\text { company with someone else }\end{array}$ & No. Patient & alone & Yes & & epends \\
\hline $\begin{array}{l}\text { 7. If family members of patients are } \\
\text { opposed to truth-telling }\end{array}$ & $\begin{array}{c}\text { Tell } \\
\text { patient }\end{array}$ & $\begin{array}{l}\text { Persuade } \\
\text { family }\end{array}$ & Postpone & $\begin{array}{c}\text { Tell } \\
\text { modestly }\end{array}$ & $\begin{array}{l}\text { Do not } \\
\text { tell }\end{array}$ \\
\hline $\begin{array}{l}\text { 8. My style of truth-telling was } \\
\text { influenced by }\end{array}$ & Philosophy & $\begin{array}{c}\text { Clinical } \\
\text { experience }\end{array}$ & Colleagues & $\begin{array}{l}\text { Moral } \\
\text { sense }\end{array}$ & $\begin{array}{l}\text { Medical } \\
\text { education }\end{array}$ \\
\hline 9. We should tell the truth indirectly & No. Tell cl & early & $\begin{array}{l}\text { Lead to } \\
\text { isunderstanc }\end{array}$ & $\operatorname{ding}$ & certain \\
\hline $\begin{array}{l}\text { 10. Truth-telling takes longer time } \\
\text { than not telling the truth }\end{array}$ & Yes & $\begin{array}{r}\text { San } \\
\text { eventu }\end{array}$ & & No & Uncertain \\
\hline 11. I feel the truth-telling as & Burden & $\begin{array}{r}\text { Burden } \\
\text { obliga }\end{array}$ & $\begin{array}{l}\text { but } \\
\text { ion }\end{array}$ & hallenging & Care less \\
\hline $\begin{array}{l}\text { 12. Percent of dying patients know } \\
\text { diagnosis }\end{array}$ & All patie & $\mathrm{nts}$ & Most patien & nts & certain \\
\hline $\begin{array}{l}\text { 13. I tell information that can lead } \\
\text { to patient's refusal to receive } \\
\text { anti-cancer treatment }\end{array}$ & Yes & $\begin{array}{l}\text { Yes, } \\
\text { implic }\end{array}$ & $\begin{array}{l}\text { In } \mathrm{n} \\
\text { to }\end{array}$ & $\begin{array}{l}\text { more detail } \\
\text { persuade }\end{array}$ & No \\
\hline $\begin{array}{l}\text { 14. Percent of dying patients know } \\
\text { that they are dying }\end{array}$ & $\begin{array}{c}\text { All } \\
\text { patients }\end{array}$ & $\begin{array}{c}\text { Most } \\
\text { patients }\end{array}$ & $\begin{array}{l}\text { Some } \\
\text { patients } \\
\text { deny }\end{array}$ & Uncertain & $\begin{array}{c}\text { All } \\
\text { patients }\end{array}$ \\
\hline $\begin{array}{l}\text { 15. I explicitly tell patients that } \\
\text { they are dying (poor prognosis) }\end{array}$ & Yes & Use eu & hemism & $\begin{array}{l}\text { No, but } \\
\text { patient knows }\end{array}$ & No \\
\hline $\begin{array}{l}\text { 16. Patients know approximately } \\
\text { how long they can live }\end{array}$ & Yes & In broa & d range & $\begin{array}{l}\text { Optimistic } \\
\text { estimate }\end{array}$ & No \\
\hline 17. I use numbers in telling patients & Yes & In bro & d range & Avoid & No \\
\hline $\begin{array}{l}\text { 18. I use statistics in telling } \\
\text { prognosis }\end{array}$ & Yes & & es, sometim & mes & No \\
\hline
\end{tabular}

